\title{
POLYMERASE CHAIN REACTION-BASED SUBTYPE DIVERSITY OF BLASTOCYSTIS SPECIES ISOLATES OBTAINED FROM HOSPITALIZED PATIENTS WITH BLASTOCYSTOSIS
}

\author{
Martin P. LALEV ${ }^{1}$, Vladislav M. NANKOV ${ }^{2}$, Ludmil S. STOYANOV ${ }^{\circledR}$, Ivelin A. ANGELOV ${ }^{3}$ \\ ${ }^{1}$ Laboratory of Parasitology, University Hospital - Pleven, Pleven, Bulgaria \\ ${ }^{2}$ University Scientific Research Laboratory, Medical University - Pleven, Pleven, Bulgaria \\ ${ }^{3}$ Department of Infectious Diseases, Epidemiology, Parasitology and Tropical Medicine, Medical \\ University - Pleven, Pleven, Bulgaria
}

Received 11 June 2020, Accepted 29 July 2020

https://doi.org/10.31688/ABMU.2020.55.3.08

\begin{abstract}
Introduction. Blastocystis sp. is a common protozoan parasite that colonizes the intestinal tract of humans and animals and in humans nine subtypes have been described so far. Gastrointestinal symptoms and/ or allergic reactions are the most common reported symptoms. It is considered that there could be a link between symptoms and the subtype of Blastocystis sp. The objective of the study was to determine the subtype of Blastocystis sp. isolates from a cohort of patients hospitalized in the University Hospital - Pleven, Bulgaria.

Material and methods. Blastocystis sp. isolates were collected from hospitalized patients who were clinically referred for parasitological testing and genomic DNA was extracted from cultivated Blastocystis sp. samples. The isolated DNA was then used to perform subtype classification using known sequence-tagged site (STS) primers and RFLP analysis of small subunit (SSU) rRNA gene.
\end{abstract}

\section{Résumé}

Diversité génotypique basée sur la PCR des isolats d'espèces de Blastocystis sp. des patients atteints de blastocystose

Introduction. Le Blastocystis sp. est un parasite protozoaire commun qui colonise le tractus gastro-intestinal chez l'homme et chez l'animal. Jusqu'à présent 9 sous-types du parasite ont été isolés chez l'homme. Les symptômes gastro-intestinaux et / ou les réactions allergiques sont les plaintes les plus fréquemment signalées. On suppose qu'il existe une relation entre les symptômes et le sous-type de Blastocystis sp.

L'objectif de l'étude a été de déterminer les isolats du sous-type de Blastocystis sp. du groupe de patients hospitalisés à l'hôpital universitaire de Pleven, Bulgarie.

Matériel et méthodes. Les isolats du Blastocystis sp. ont été prélevés à partir de patients hospitalisés, indiqués pour un examen parasitologique et l'ADN génomique a été extrait des échantillons du Blastocystis 
Results. Blastocystis sp. was isolated from 42 out of the 261 tested patients - a prevalence of $16.09 \%$. Out of the 42 Blastocystis sp. positive fecal samples, DNA was successfully extracted from 33 . The isolated DNA belonged only to two subtypes - ST1 and ST3. No mixed subtypes were detected.

Conclusions. We found that ST3 was more prevalent among patients with clinically presenting allergic diseases - 17 of the tested patients (65.38\%). ST1 was isolated from patients with allergic and with gastro-intestinal symptoms.

Keywords: blastocystis, PCR, subtype, blastocystosis.

\section{Abbreviations:}

$$
\begin{aligned}
& \text { ST = subtype } \\
& \mathrm{PCR}=\text { polymerase chain reaction } \\
& \mathrm{IBS}=\text { irritable bowel syndrome }
\end{aligned}
$$

\section{INTRODUCTION}

Blastocystis sp. is a common protozoan parasite that colonizes the intestinal tract of humans and animals ${ }^{1}$. It has a worldwide distribution and is especially common in some regions of Asia and Africa, where it is isolated from more than $50 \%$ of human fecal samples ${ }^{2-4}$. Blastocystis sp. has several morphological forms - vacuolar, granular, amoeboid, and cyst form. It is considered that the amoeboid form is pathogen$i^{5}$. Molecular studies have shown that Blastocystis sp. has high genetic variability and has been classified into 17 subtypes $^{6}$. Nine subtypes have been isolated from humans so far (ST1 - ST9) ${ }^{7,8}$. Subtype distribution varies around the world, with ST1, ST3 and ST4 being the most common in Europe; in the USA, ST1 and ST2 are more prevalent, and in Asia and Australia ST1 and ST ${ }^{9-11}$. ST3 is the most common isolated subtype from humans, as it accounts for $60 \%$ of Blastocystis sp. isolates from humans, according to most epidemiological studies ${ }^{12}$. Co-infections between more than one subtype are also possible (usually ST1 and ST3) ${ }^{13}$.

The pathogenetic potential of Blastocystis sp. is controversial and a subject of debate. The most common reported symptoms are gastrointestinal (abdominal pain, diarrhea, vomiting) and/or allergic reactions (acute or chronic urticaria) $)^{14}$.

The OBJective OF OUR STUdY was to determine the subtype of Blastocystis sp. isolates from a cohort of patients hospitalized in the University Hospital Pleven, Bulgaria. sp. L'ADN isolé a été utilisé pour la classification des sous-types par des amorces de sites marqués par séquence (STS) connus et l'analyse RFLP du petit gène de la sous-unité d'ARNr.

Résultats. Le Blastocystis sp. a été isolé chez 42 des 261 patients étudiés - une prévalence de 16,09\%. Parmi les 42 échantillons fécaux positifs du Blastocystis sp. l'ADN a été isolé avec succès sur 33. Deux sous-types ont été isolés - ST1 et ST3. Aucun sous-type mixte n'a été isolé.

Conclusions. Nous avons constaté que ST3 est plus fréquent chez les patients souffrant de maladies allergiques - 17 des patients étudiés (65,38\%). ST1 a été isolé chez des patients allergiques et chez des patients présentant des symptômes gastro-intestinaux.

Mots-clés: blastocystis, PCR, sous-type, blastocystose.

\section{Material AND Methods}

During the period January- July 2019, 261 hospitalized patients were tested for Blastocystis sp. in the parasitological laboratory of the University Hospital of Pleven, Bulgaria. The reported symptoms can be grouped into two main groups - allergic or gastro-intestinal symptoms. From the tested 261 patients, $147(56.32 \%)$ were female and $114(43.68 \%)$ male. The mean age of the study group was 44 years (SD $44.56 \pm 22.3)$.

The diagnosis of blastocystosis was performed via light microscopy of fecal samples delivered to the laboratory in sterile fecal containers. An iodine solution stained wet mound of fecal material was studied from each sample at 40x magnification. Positive Blastocystis sp. fecal samples were inoculated in the Jones' medium and incubated twice at $37^{\circ} \mathrm{C}$ for 48 hours. The media were then studied using light microscopy for the presence of Blastocystis sp. and were subjected to centrifugation with physiological solution. The resulting sediment was stored at $-20^{\circ} \mathrm{C}$ until PCR genotyping.

Genomic DNA was extracted using the "QuickDNA ${ }^{\text {TM }}$ Miniprep Plus Kit (Zymo Research, USA)“ according to the manufacturer's instructions. Genomic DNA of each sample was stored at $-20^{\circ} \mathrm{C}$ until further use.

PCR typing was performed using the diagnostic primer sets SB83, SB155, SB227, SB332, SB336, SB337 and SB340 as described previously (Yoshikawa et al., 2004) ${ }^{15}$. Primer sequences were taken from Yoshikawa et al. and are given in Table 1.

PCR conditions included one cycle denaturation at $94^{\circ} \mathrm{C}$ for 4 minutes, 35 cycles consisting of 
Table 1. Subtype classification of Blastocystis sp. using sequence-tagged site (STS) primer sets

\begin{tabular}{|c|c|c|c|c|c|}
\hline $\begin{array}{l}\text { Primer } \\
\text { set }\end{array}$ & $\begin{array}{l}\text { Product } \\
\text { size } \\
(\mathrm{bp})\end{array}$ & $\begin{array}{c}\text { Sequence of forward }(\mathrm{F}) \text { and reverse ( } \mathrm{R}) \\
\text { primers } \\
\left(5^{\prime} \text { to } 3^{\prime}\right)\end{array}$ & Subtype & $\begin{array}{c}\text { GenBank } \\
\text { accession } \\
\text { no. }\end{array}$ & Reference \\
\hline SB83 & 351 & $\begin{array}{c}\text { F: GAAGGACTCTCTGACGATGA } \\
\text { R: GTCCAAATGAAAGGCAGC }\end{array}$ & 1 & AF166086 & Yoshikawa et al. $(2004)^{15}$ \\
\hline SB155 & 650 & $\begin{array}{l}\text { F: ATCAGCCTACAATCTCCTC } \\
\text { R: ATCGCCACTTCTCCAAT }\end{array}$ & 2 & AF166087 & Yoshikawa et al. (2004) \\
\hline SB227 & 526 & $\begin{array}{c}\text { F: TAGGATTTGGTGTTTGGAGA } \\
\text { R: TTAGAAGTGAAGGAGATGGAAG }\end{array}$ & 3 & AF166088 & Yoshikawa et al. (2004) \\
\hline SB332 & 338 & $\begin{array}{c}\text { F: GCATCCAGACTACTATCAACATT } \\
\text { R: CCATTTTCAGACAACCACTTA }\end{array}$ & 4 & AF166091 & Yoshikawa et al. (2004) \\
\hline SB336 & 317 & $\begin{array}{l}\text { F: GTGGGTAGAGGAAGGAAAACA } \\
\text { R: AGAACAAGTCGATGAAGTGAGAT }\end{array}$ & 6 & AY048751 & Yoshikawa et al. $(2004)^{15}$ \\
\hline SB337 & 487 & $\begin{array}{l}\text { F: GTCTTTCCCTGTCTATTCTGCA } \\
\text { R: AATTCGGTCTGCTTCTTCTG }\end{array}$ & 7 & AY048750 & Yoshikawa et al. (2004) \\
\hline SB340 & 704 & $\begin{array}{l}\text { F: TGTTCTTGTGTCTTCTCAGCTC } \\
\text { R: TTCTTTCACACTCCCGTCAT }\end{array}$ & 5 & AY048752 & Yoshikawa et al. $(2004)^{15}$ \\
\hline
\end{tabular}

Table 2. Prevalence of isolated Blastocystis sp. subtypes

\begin{tabular}{ccccc}
\hline Subtype & Subtype 1 (ST1) & Subtype 3 (ST3) & Unknown & Total \\
\hline $\mathrm{N}(\%)$ & $7(16.67 \%)$ & $26(61.90 \%)$ & $9(21.43 \%)$ & $42(100 \%)$ \\
\hline
\end{tabular}

Table 3. Prevalence of isolated subtypes based on diagnosis

\begin{tabular}{ccccc}
\hline Diagnosis & ST1 & ST3 & Unknown & Total \\
\hline Angioedema & - & $1(3.85 \%)$ & & $1(2.38 \%)$ \\
\hline Atopic dermatitis & $1(14.29 \%)$ & $2(7.69 \%)$ & - & $3(7.14 \%)$ \\
\hline Bronchial asthma & - & $2(7.69 \%)$ & $1(11.11 \%)$ & $3(7.14 \%)$ \\
\hline Dermatosis & - & - & $1(11.11 \%)$ & $1(2.38 \%)$ \\
\hline Acute urticaria & - & $6(23.08 \%)$ & $5(55.56 \%)$ & $11(26.19 \%)$ \\
\hline Chronic urticaria & $2(28.57 \%)$ & $6(23.08 \%)$ & $1(11.11 \%)$ & $9(21.43 \%)$ \\
\hline Gastro-intestinal symptoms & $4(57.14 \%)$ & $9(34.61 \%)$ & $1(11.11 \%)$ & $14(33.33 \%)$ \\
\hline Total & $7(100 \%)$ & $26(100 \%)$ & $9(100 \%)$ & $42(100 \%)$ \\
\hline
\end{tabular}

denaturation at $95^{\circ} \mathrm{C}$ for 30 seconds, annealing at $52^{\circ} \mathrm{C}$ for 30 seconds, extension at $72^{\circ} \mathrm{C}$ for 30 seconds and a final extension step at $72^{\circ} \mathrm{C}$ for 3 minutes. The amplification products were separated by electrophoresis on a $2 \%$ agarose gel containing ethidium bromide and were visualised with ultraviolet light. Subtype classification was performed according to results published by Yoshikawa et al. The size of the amplification products produced with each of the diagnostic primer sets was compared with the published amplicon sizes (as shown in Table 1) and the different subtypes were determined accordingly.

\section{Results}

Blastocystis sp. was isolated from 42 out of the 261 tested patients - a prevalence of $16.09 \%$. Twenty-three of the positive patients were female
(15.65\%) and 19 were male (16.67\%). Out of the 42 Blastocystis sp. positive fecal samples, DNA was successfully extracted from 33. In our study, we used primer sets for 7 subtypes of Blastocystis sp. (Table 1). The isolated DNA belonged only to two subtypes, ST1 and ST3. The prevalence of isolated subtypes in our study is shown in Table 2 . Figures 1 and 2 show the PCR typing results obtained using the diagnostic primer sets SB227 and SB83 that correspond to subtypes 3 and 1, respectively. Table 3 shows the subtype prevalence according to the clinical diagnosis indicated for parasitological testing.

\section{Discussion}

In this study, we analyzed the distribution of Blastocystis sp. subtypes among hospitalized patients in the University Hospital - Pleven, Bulgaria. This 


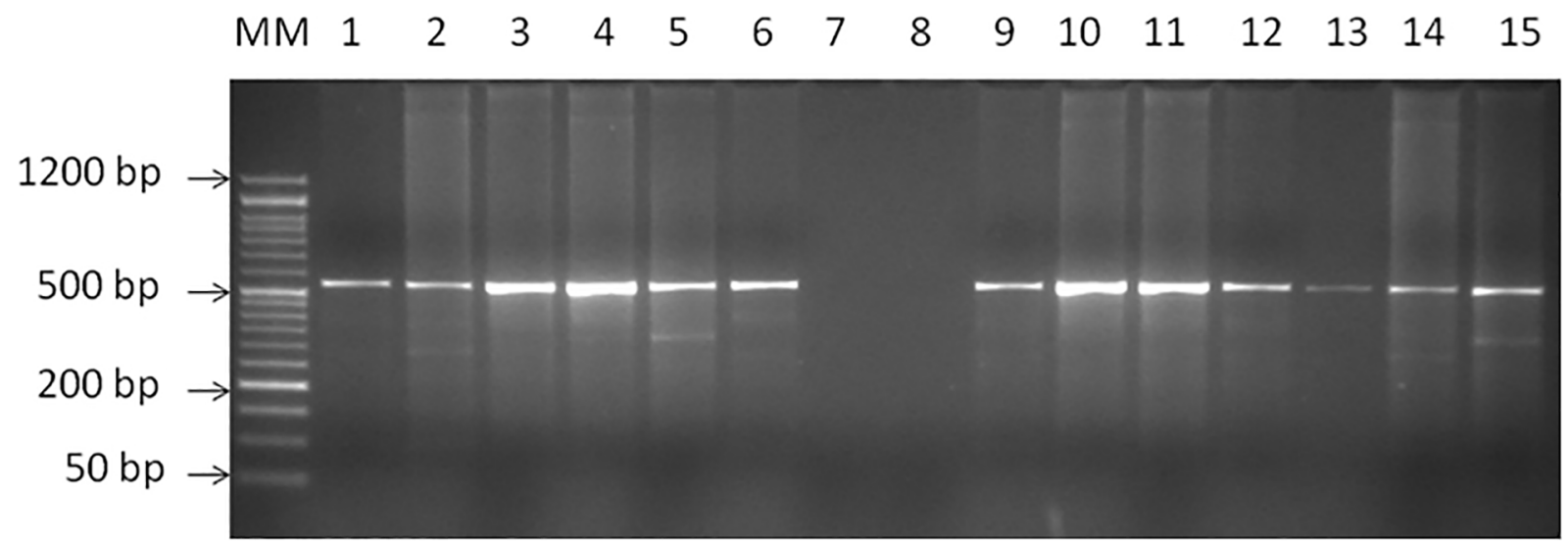

Figure 1. Multiplication of Blastocystis sp. isolates by specific primer pair SB227 for subtype 3. The resulting fragment is 526 nucleotide pairs in length. 15 different samples were tested, using a molecular marker (MM) to determine the size of the amplification product.

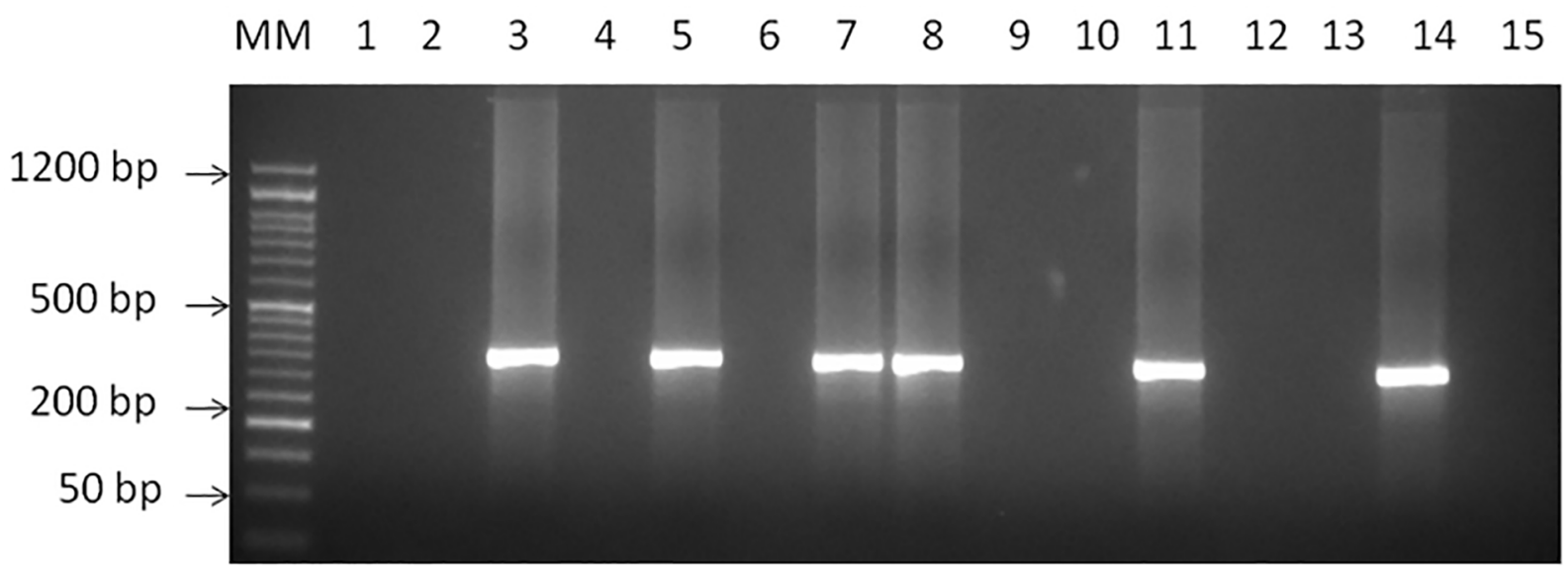

Figure 2. Multiplication of Blastocystis sp. isolates with a specific primer pair SB83 for subtype 1. The resulting fragment is 351 nucleotide pairs in length. 15 different samples were tested and a molecular marker (MM) was used to determine the size of the amplification product.

is the second such study in the country ${ }^{16}$. The prevalence of Blastocystis sp. is $16.09 \%$, which is according to similar studies among hospitalized patients in the Netherlands $-24.2 \%{ }^{4}$, in patients from a referral centre for parasitic infections in North Italy $(50.68$ $\%)^{17}$ and in a large-scale multi-center study from 11 hospitals in France - 18.1\% ${ }^{18}$.

Most studies about the prevalence of Blastocystis sp. don't show any correlation between sex and isolation of the parasite ${ }^{4,18}$. In our study, we did not find any statistical difference regarding infection rates between males and females (16.67\% and $15.65 \%$, respectively).

From the isolated Blastocystis sp. subtypes, ST3 is the dominant one, found in $61.90 \%$ of cases (Table 2). The prevalence of ST3 among our cohort of patients matches results from other similar studies made in Europe ${ }^{13,19-21}$. ST1 was isolated from 16.67\% of the genotyped samples (ST1). This subtype is the second most common isolated one after ST3 in other European countries ${ }^{19,20}$. Although ST4 is also found in Europe, it was not found in our study.

The patients in our study had either clinical allergy (mainly acute or chronic urticaria) or gastro-intestinal symptoms in the form of irritable bowel syndrome (IBS). These symptoms were the reason of referral for parasitological testing.

We found that ST3 was more prevalent among patients with clinically manifest allergic diseases - 17 of the tested patients (65.38\%) (Table 3). ST3 was also found in 9 patients with gastro-intestinal symptoms (34.62\%). According to literature data, ST3 has been associated both with acute or chronic urticaria and IBS; however, it has also been isolated from healthy patients ${ }^{22-24}$. The numbers of ST3-related Blastocystosis cases in our study are too few to claim a possible statistical correlation between the clinical presentation and Blastocystis subtype in both groups 
of patients. Similarly, we found ST1 in both group of patients. Other studies have shown ST1 to be more common in IBS patients ${ }^{25}$.

\section{Conclusions}

Our study on Blastocystis sp. subtype diversity is the first one performed in Bulgaria on a large group of patients. We found a distribution of two subtypes (ST1 and ST3), which matches subtype isolation and distribution in Europe. We tested patients with different Blastocystis associated diagnoses, however at this point we cannot conclusively make a connection between subtype and clinical presentation, due to the small number of cases and the limited scope of this study.

Additional epidemiological and clinical studies will be necessary to show the distribution of Blastocystis sp. subtypes in other regions of Bulgaria and association with the clinical presentation of Blastocystosis.

\section{Author Contributions}

Conceptualization, I.A.A. and M.P.L.; methodology, I.A.A. and L.S.S.; software, V.M.N.; validation, I.A.A. and L.S.S.; formal analysis, I.A.A.; investigation, M.P.L. and L.S.S.; resources, I.A.A. and V.M.N.; data curation, I.A.A., M.P.L., L.S.S. and V.M.N.; writing-original draft preparation, I.A.A.; writing-review and editing, M.P.L., L.S.S. and V.M.N.; visualization, I.A.A., L.S.S. and V.M.N.; supervision, I.A.A.; project administration, L.S.S. All the authors have read and agreed with the final version of the article.

\section{Compliance with Ethical Requirements:}

"The authors declare no conflict of interest regarding this manuscript. The study has been approved by the University Ethics Committee for Scientific Studies and is a project funded by the Medical University - Pleven."

„The authors declare that all the procedures and experiments of this study respect the ethical standards in the Helsinki Declaration of 1975, as revised in 2008(5), as well as the national law."

\section{Acknowledgements:}

„The study has been approved by the University Ethics Committee for Scientific Studies and is a project funded by the Medical University - Pleven, Bulgaria."

\section{References}

1. Skotarczak B. Genetic diversity and pathogenicity of Blastocystis. Ann Agric Environ Med 2018;25(3):411-416.
2. Rojas-Velázquez L, Morán P, Serrano-Vázquez A, et al. Genetic diversity and distribution of Blastocystis subtype 3 in human populations, with special reference to a rural population in central Mexico. Biomed Res Int 2018;2018:3916263.

3. Sekar U, Mariappan S. Recent insights into the genetic diversity, epidemiology and clinical relevance of Blastocystis species. JMR 2015;1(1): 33-39.

4. Bart A, Wentink-Bonnema EM, Gilis H, et al. Diagnosis and subtype analysis of Blastocystis sp. in 442 patients in a hospital setting in the Netherlands. BMC Infect. Dis 2013;13: 389.

5. Parija SC, Jeremiah S. Blastocystis: Taxonomy, biology and virulence. Trop Parasitol 2013;3(1): 17-25.

6. Lepczyńska M, Białkowska J, Dzika E, Piskorz-Ogórek K, Korycińska J. Blastocystis: how do specific diets and human gut microbiota affect its development and pathogenicity? Eur J Clin Microbiol Infect Dis 2017;36(9): 1531-1540.

7. Zhang W, Ren G, Zhao W, et al. Genotyping of Enterocytozoon bieneusi and subtyping of Blastocystis in cancer patients: relationship to diarrhea and assessment of zoonotic transmission. Front Microbiol 2017;8: 1835.

8. Stensvold CR. Blastocystis: genetic diversity and molecular methods for diagnosis and epidemiology. Trop Parasitol 2013;3: 26-34

9. Roberts T, Ellis J, Harkness J, Marriott D, Stark D. Treatment failure in patients with chronic Blastocystis infection. J Med Microbiol 2014;63(Pt 2): 252-7.

10. Valença Barbosa C, de Jesus Batista R, Pereira Igreja R, d'Avila Levy CM, Werneck de Macedo H, Carneiro Santos HL. Distribution of Blastocystis subtypes isolated from humans from an urban community in Rio de Janeiro, Brazil. Parasit Vectors 2017;10(1): 518.

11. Deng L, Chai Y, Zhou Z, et al. Epidemiology of Blastocystis sp. infection in China: a systematic review. Parasite 2019;26: 41.

12. Cian A, El Safadi D, Osman M, et al. Molecular epidemiology of blastocystis sp. in various animal groups from two French zoos and evaluation of potential zoonotic risk. PLoS One 2017;12(1)

13. Alfellani MA, Taner-Mulla D, Jacob AS, et al. Genetic diversity of Blastocystis in livestock and zoo animals. Protist 2013;164(4): 497-509.

14. Roberts T, Stark D, Harkness J, Ellis J. Update on the pathogenic potential and treatment options for Blastocystis sp. Gut Pathog 2014;6: 17.

15.Yoshikawa H, Wu Z, Kimata I, et al. Polymerase chain reaction-based genotype classification among human Blastocystis hominis population isolated from different countries. Parasitol Res 2004:92(1): 22 - 9.

16.Angelov I., N. Tzvetkova, A. Velkova, R. Kurdova. PCR based identification of blastocysts isolates from humans. Infectology 2010;47(2): 44-47.

17. Piubelli C, Soleymanpoor H, Giorli G, et al. Blastocystis prevalence and subtypes in autochthonous and immigrant patients in a referral centre for parasitic infections in Italy. PLoS One 2019;14(1)

18. El Safadi D, Cian A, Nourrisson C, et al. Prevalence, risk factors for infection and subtype distribution of the intestinal parasite Blastocystis sp. from a large-scale multi-center study in France. BMC Infect. Dis 2016;16 (1): 451.

19. Souppart L, Sanciu G, Cian A, et al. Molecular epidemiology of human Blastocystis isolates in France. Parasitol Res 2009;105(2): 413-421. 
20. Meloni D, Sanciu G, Poirier P, et al. Molecular subtyping of Blastocystis sp. isolates from symptomatic patients in Italy. Parasitol Res 2011;109(3): 613-619.

21. Stensvold R, Brillowska-Dabrowska A, Nielsen H, Arendrup $\mathrm{M}$. Detection of Blastocystis hominis in unpreserved stool specimens by using polymerase chain reaction. J Parasitol 2006;92: 1081-1087.

22. Hameed DM, Hassanin OM, Zuel-Fakkar NM. Association of Blastocystis hominis genetic subtypes with urticaria. Parasitol Res 2011;108(3): 553-560.
23. Casero RD, Mongi F, Sánchez A, Ramírez JD. Blastocystis and urticaria: Examination of subtypes and morphotypes in an unusual clinical manifestation. Acta Trop 2015;148: 156-161.

24. El-Badry A, Abd El Wahab W, Hamdy D, Aboud A. Blastocystis subtypes isolated from irritable bowel syndrome patients and co-infection with Helicobacter pylori. Parasitol Res. 2018;117(1): 127-137.

25. Wawrzyniak I, Poirier P, Viscogliosi E, et al. Blastocystis, an unrecognized parasite: an overview of pathogenesis and diagnosis. Ther Adv Infect Dis 2013;1(5): 167-178. 